\title{
Immunocytochemical localization of heat-shock protein 60-related protein in Beta-cell secretory granules and its altered distribution in non-obese diabetic mice
}

\author{
K. Brudzynski ${ }^{1}$, V.Martinez ${ }^{2}$ and R.S. Gupta ${ }^{3}$ \\ Departments of ${ }^{1}$ Medicine and ${ }^{2}$ Pathology, University of Western Ontario, London, and \\ ${ }^{3}$ Department of Biochemistry, McMaster University, Hamilton, Ontario, Canada
}

\begin{abstract}
Summary. Immuno-electron microscopy technique was employed to investigate the cellular distribution of $60 \mathrm{kDa}$ heatshock protein (HSP60) in pancreatic Beta cells of control and non-obese diabetic mice. In thin sections prepared from control mice, antibody to mammalian HSP60 cross-reacted with protein(s) located to mitochondria and secretory granules. In particular, prominent binding of the antibody was seen to the insulin core of the mature insulin-secreting granules. In comparison, very little immunoreactivity was observed with immature secretory granules or with the Golgi apparatus. No binding to secretory granules or mitochondria was observed with normal mouse serum or with unrelated sera. On Western blots, HSP60 antibody specifically interacted with a single $62 \mathrm{kDa}$ islet cell protein. These results suggest the existence of an HSP60-related protein with a novel location in mature se-
\end{abstract}

cretory granules of Beta cells. The preferential association of the HSP60-related protein with the insulin core was gradually lost in Beta cells of pre-diabetic non-obese diabetic mice, and correlated with the progression of insulitis. The decrease in the granular binding of the HSP60 antibody was accompanied by an increase in cytoplasm staining, and was concomitant with a significant expansion of the insulin core diameter. The altered distribution of the HSP60-related protein in prediabetic mice, together with our observation that immature secretory granules accumulate in these animals indicate that the presence of HSP60-related protein in secretory granules might be associated with the secretory function of Beta cells.

Key words: Heat-shock protein, HSP60, secretory granules, Type 1 (insulin-dependent) diabetes mellitus
The initial cause of autoimmunity against Beta cells and the sequence of events that leads to massive lymphocytic infiltration of islets (insulitis) and specific destruction of insulin-secreting cells remains unknown. Over the last few years, it has become clear that some autoimmune reactions can be provoked by heat-shock proteins. The term heat-shock, or stress proteins, refers to a group of major cellular proteins (many of which are constitutively expressed at a high level) whose synthesis is induced to a varying extent by stress such as heat shock or infection. One prominent group of heat-shock proteins, commonly referred to as HSP60 or $60-65 \mathrm{kDa}$ antigens, consist of proteins which are major antigens of a wide variety of pathogenic organisms [1-3]. The homologues of HSP60 are shown to be present in all species ranging from bacteria and plants to humans, and their primary structure is highly conserved across all species. Recent studies provide evidence that these proteins perform a highly-conserved "molecular chaperone" role in proper folding of newly-synthesized polypeptide chains and their assembly into oligomeric protein complexes [4-7]. The strong antigenic nature and high degree of sequence conserva- tion between HSP 60 of the infecting organism and that of the host is suspected to play an important role in the triggering of immune responses including autoimmunity [2, 8 ]. Indeed, immune responses against a $65 \mathrm{kDa}$ mycobacterial heat-shock protein (HSP60) has been implicated in the aetiology of rat adjuvant arthritis $[9,10]$ and rheumatoid arthritis $[11,12]$ and, recently, also in aetiology of human and non-obese diabetic (NOD) mouse Type 1 (insulin-dependent) diabetes mellitus $[13,14]$. In view of recent reports that Beta-cell autoantigen is cross-reactive with mycobacterial HSP60 and that mouse diabetogenic T-cell clones are strongly stimulated by human HSP $60[13$, 14], we have investigated the cellular localization of HSP60 in pancreatic islet cells of normal and pre-diabetic NOD mice.

\section{Materials and methods}

\section{Animals}

The NOD mouse strain [15] was obtained from the University of Colorado (Denver, Co, USA), and has been maintained by inbreeding at the Robarts Research Institute. Beginning at 4 weeks of age, 
mice were routinely monitored for blood glucose and urinary glucose levels with Diastix and Ketostix reagent strips (Ames Division Miles Lab. Ltd., Etobicoke, Ontario, Canada).

Mice were classified as "pre-diabetic" on the basis of histological evidence of insulitis, but with blood glucose and plasma insulin levels in normal range (below $13.8 \mathrm{mmol} / \mathrm{l}$ and between $71.8-107.9 \mathrm{pmol} / 1$, respectively). Diabetes in NOD mouse strain occurs in an age- and sex-dependent manner, (between the 20th and 30th week of age, and with about $75 \%$ and $10 \%$ incidence in the female and male mouse, respectively). The term "pre-diabetic" relates to the prodromal phase in mice aged 4- to 20-weeks-old and does not preclude that any particular NOD mouse will develop diabetes.

Female pre-diabetic, 4-13-week-old NOD mice and agematched control (SJL) mice were used throughout these experiments. The mean plasma glucose level determined by glucose analyser (Abbot Diagnostic) was $7.83 \mathrm{mmol} / \mathrm{l} \pm 0.49$ (SEM).

\section{Insulitis determination}

Formalin-fixed, paraffin-embedded sections of the pancreas $(5 \mu \mathrm{m})$ were stained with haematoxylin and eosin and were examined for the presence of insulitis, as described [16].

\section{Antibody}

The rabbit polyclonal antibody used in these studies has been raised against HSP60 from Chinese hamster ovary cells, and it binds specifically to this protein in one- and two-dimensional immunoblots of mammalian cells $[17,18]$. Primary antiserum and control normal rabbit serum, as well as unrelated sera (normal human or mouse serum), were used at 1:100 to 1:200 dilution.

\section{Electron microscopy}

Pancreatic tissue from female, 5-, 7- and 13-week-old pre-diabetic, NOD mice ( $n=3 /$ age group) and age-matched control SJL mice ( $n=3$ /age group) were used in this study. All tissue samples were fixed in $2.5 \%$ glutaraldehyde in $0.1 \mathrm{mmol} / /$ cacodylate buffer, $\mathrm{pH} 7.2$, overnight, washed in cacodylate buffer, osmium tetroxide-postfixed, gradually dehydrated in ethanol, and embedded in Epon/Araldite. Thin sections were cut and collected on nickel grids.

\section{Immunogold ultracytochemistry}

Grids were washed in drops of $\mathrm{dH}_{2} \mathrm{O}$, then either etched in saturated sodium metaperiodate [19], or directly treated with phosphate buffered saline (PBS) containing 1\% bovine serum albumin (BSA). (Both methods gave comparable results). The sections were incubated overnight with a primary antibody (1:100 to 1:200 dilution) at $4^{\circ} \mathrm{C}$, washed extensively with PBS, and then incubated with $10-\mathrm{nm}$ colloidal gold-protein A solution (1:40 dilution in PBS/1\% BSA) or 20-nm colloidal gold coated goat anti-rabbit IgG (Sigma, St. Louis, Mo, USA) for $30 \mathrm{~min}$ at room temperature. After jet washing in PBS and distilled water, the grids were counterstained with uranyl acetate and lead citrate, and viewed in a Zeiss 109 electron microscope.

The non-specific binding of gold conjugates was evaluated by replacement of primary antibodies by PBS (artifacts of immunogold labelling) or non-related antisera (specificity of staining).

\section{Double-immunogold labelling}

Double-immunogold labelling was performed on the same thin-section of the Beta cells with the gold particles of different sizes. One side of the tissue section was incubated with the anti-HSP60 antibody and 20-nm colloidal gold/secondary antibody complex. After the grid was dried, the second side of the section was incubated with the anti-insulin antibody followed by protein A-gold complex formed with 10-nm gold particles. After all labellings were completed, the grids were contrasted with uranyl acetate and lead citrate.

\section{Immunocytochemical localization of proinsulin-rich granules}

Thin sections of glutaraldehyde-fix rat islet cells were embedded in Lowicryl and incubated with the proinsulin-specific monoclonal antibody (GS-9A8) followed by staining with a secondary antibody and protein A-gold, as described in 1985 by Orci et al. [20]. Mouse monoclonal antibody GS-9A8 was obtained from Dr. O.Madsen (Hagedorn Research Laboratory, Gentofte, Denmark).

\section{Quantitation of labelling}

Electron micrographs were photographed at $20000 \times$ and then printed to give a final magnification of $54000 \times$. The distribution of gold particles within different cellular compartments in islets of control mice were analysed using Bioquant System IV (R and M Biometrics Inc. Nashville, Tenn., USA) by relating the area occupied by each compartment with the superimposed gold count. A total of 21 photographs were evaluated.

\section{Isolation of islet cells}

Islets of Langerhans were isolated according to the method of Lacy and Kostianovsky [21]. Briefly, pooled pancreata from three to six mice were finely chopped and digested for from 2-3 min with $1.5 \mathrm{mg} / \mathrm{ml}$ of collagenase P (Boehringer Mannheim, Mannheim, FRG) in HEPES buffered salt solution (HBSS) at $37^{\circ} \mathrm{C}$ in a shaking water bath. The digest was washed by centrifugation and islets were hand-picked, counted and plated on $50 \mathrm{~mm}$ diameter culture dishes in RPMT 1640 medium supplemented with $11.1 \mathrm{mmol} / 1$ glucose, antibiotics and $10 \%$ fetal calf serum (FCS). The islets were allowed to recouperate in culture for $24 \mathrm{~h}$ at $37^{\circ} \mathrm{C}$. Only islets which were visibly free of adhering exocrine tissue were selected for use in these experiments.

A sample of cadaver human islets (500 islets) were obtained from Dr. P.Zucker (Multi-Organ Transplant Service of University Hospital, London, Ontario, Canada).

\section{Immunoprecipitation and immunoblotting}

Batches of 30 to 50 islets were lysed by several cycles of freezing and thawing in a 0.3 to $0.5 \mathrm{ml}$ of buffer containing $20 \mathrm{mmol} / \mathrm{l}$ Tris- $\mathrm{HCl}$, $\mathrm{pH} 7.4,150 \mathrm{mmol} / \mathrm{l} \mathrm{NaCl}, 1000 \mathrm{KIE} / \mathrm{ml}$ aprotinin, and $2 \mathrm{mmol} / \mathrm{l} \mathrm{phe}-$ nylmethylsulphonyl fluoride. Aliquots of $100 \mu$ islet cell lysate were pre-cleared by incubation ( $7 \mathrm{~h}$ at $4^{\circ} \mathrm{C}$ ) with $25 \mu \mathrm{l}$ normal sera, and were followed by adsorption to SAC cells (Staphylococcus aureus cells, Calbiochem, La Jolla, Calif., USA) and incubated with $25 \mu \mathrm{l}$ of test sera overnight at $4^{\circ} \mathrm{C}$ with continuous shaking. Immune complexes were isolated by incubation with pre-swollen protein ASepharose $\left(100 \mu \mathrm{l}\right.$ per sample) for $2 \mathrm{~h}$ at $4^{\circ} \mathrm{C}$. After several washes with buffer containing $0.3 \mathrm{~mol} / 1 \mathrm{NaCl}, 2 \%$ (NP40), $0.2 \%$ SDS and $0.02 \mathrm{~mol} / 1$ sodium phosphate, $\mathrm{pH} 7.2$, and buffer containing $10 \mathrm{mmol} / 1$ Tris- $\mathrm{HCl}, \mathrm{pH} 7.5$ and $0.1 \%$ NP40, immune complexes bound to Sepharose were denatured by boiling for $5 \mathrm{~min}$ in a sample buffer containing $80 \mathrm{mmol} / \mathrm{l}$ Tris-HCl, $\mathrm{pH} 6.8,3 \%$ SDS, $15 \%$ sucrose, $0.001 \%$ bromophenol blue and $5 \%$ beta-mercaptoethanol.

Proteins eluted from protein A-Sepharose by centrifugation were separated in $10 \%$ SDS-PAGE and transferred onto immobilon membrane. The antigens were detected by incubation of membranes with primary antibodies (HSP60 antibody or control, normal mouse or human sera) followed by incubation with horseradish peroxidase- 


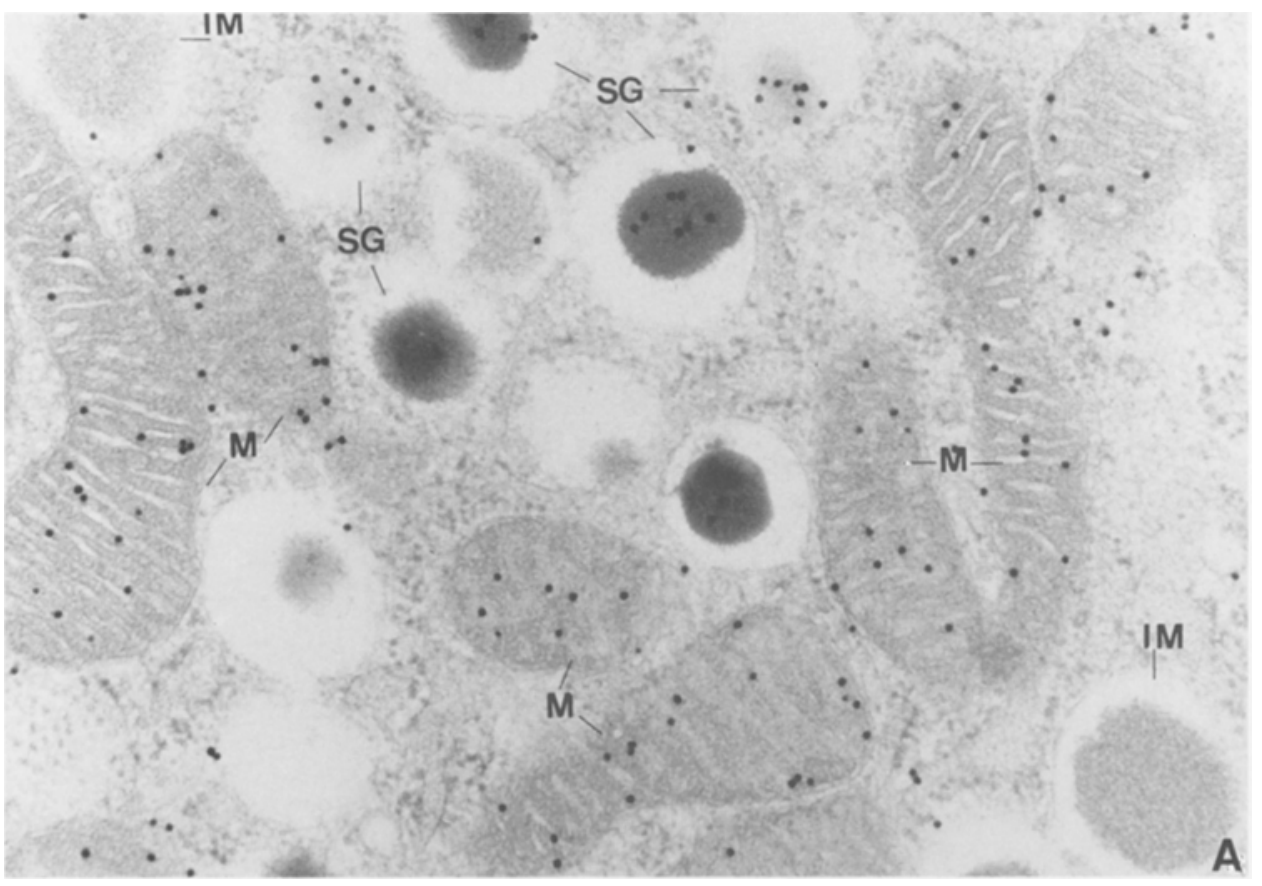

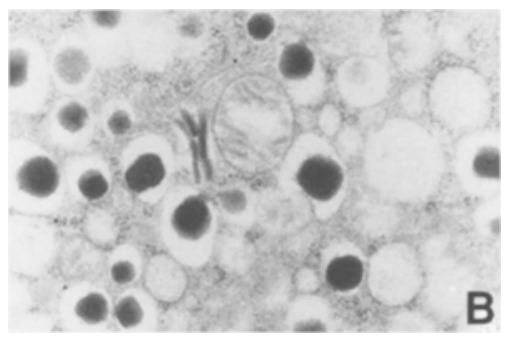

Fig. 1A, B. Localization of binding sites of antibody to the HSP60 in pancreatic islet cells of control SJL mouse detected by immunogold technique. A Gold particles are concentrated over mitochondria and the dense secretory material of secretory granules. B Control experiment with non-immune rabbit serum did not show any immunogold staining of these organelles. SG, secretory granules; IM, immature secretory granules; M, mitochondria conjugated secondary antibodies (Jackson Immunoresearch Laboratory, West Grove, Pa., USA).

\section{Statistical analysis}

The immunogold densities (gold counts/area ratio) were statistically analysed using the one-way ANOVA and $t$-test.

\section{Results}

\section{Localization of HSP60 in insulin secretory granules of pancreatic islet cells}

To identify the location of the antigen bound by the antibody to mammalian HSP60, thin sections of mouse pancreatic islet cells were examined by electron microscopy and immunogold technique. A strong immunoreactivity restricted to secretory granules (SGs) and mitochondria was observed (Fig. 1 A). Among SGs of islet cells, one type of granule persistently showed exceptionally high immunoreactivity. The morphology of the granules and results of double-immunogold labelling with anti-insulin and HSP60 antibodies indicated that they corresponded to insulin SGs (Fig.2). In control experiments where the primary antibody was replaced by normal rabbit serum, no staining of SGs and mitochondria was seen which indicated that the observed binding was specific (Fig.1B). Similarly, when an incubation with the primary antibody was omitted very few gold particles randomly distributed over different cellular structures were found.

Staining of tissue sections with anti-insulin antibody alone revealed that it reacted with Beta-cell granules at different stages of maturation - including the immature, maturating and mature SGs (Fig. $3 \mathrm{~A}$ ). In comparison to the insulin antibody binding, the distribution of HSP60 binding sites among the population of Beta-cell granules was not uniform (Fig. 3 B). Immature, clathrin-coated secretory granules with a non-condensed inner core filled with the proinsulin contained very few HSP60 binding sites (Fig. 3 B, C) [20]. In contrast, the mature granules with the characteristic dense insulin core strongly reacted with HSP60 antibody, and the labelling in these was predominantly concentrated over the dense insulin core (Fig. 1A, 2, 3B).

Quantitative evaluation of the immuno-gold distribution among different cellular compartments confirmed the qualitative observation on the preferential binding of

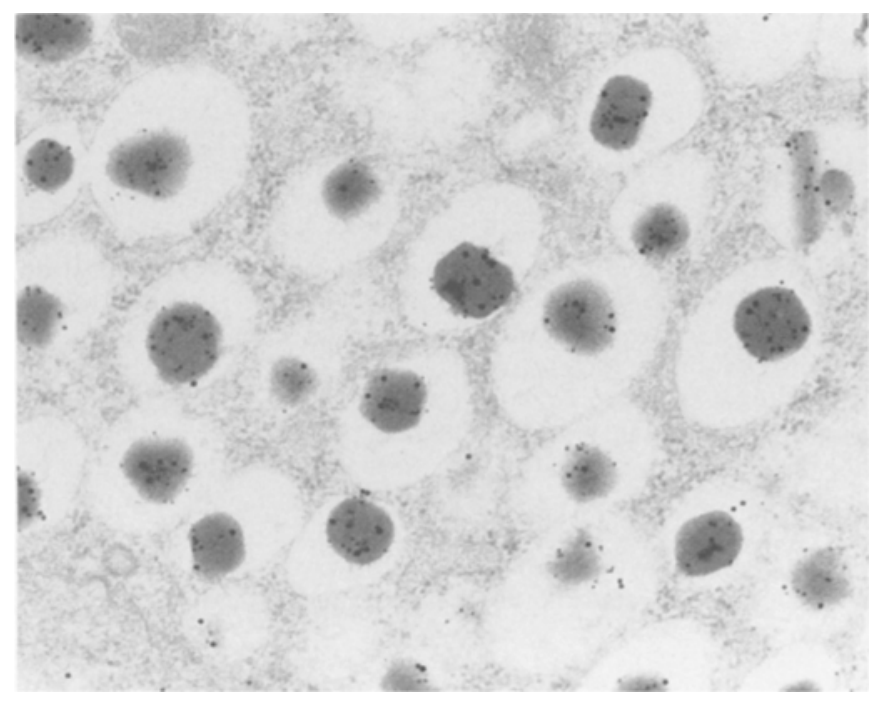

Fig. 2. Electron micrograph of islet cells from a 5-week-old prediabetic female NOD mouse labelled by double-immunogold technique with anti-HSP60 antibody ( $20 \mathrm{~nm}$ gold particles) and antiinsulin antibody (10 $\mathrm{nm}$ gold particles). The secretory granules predominantly stained with anti-HSP60 antibody are also recognized by anti-insulin antibody 


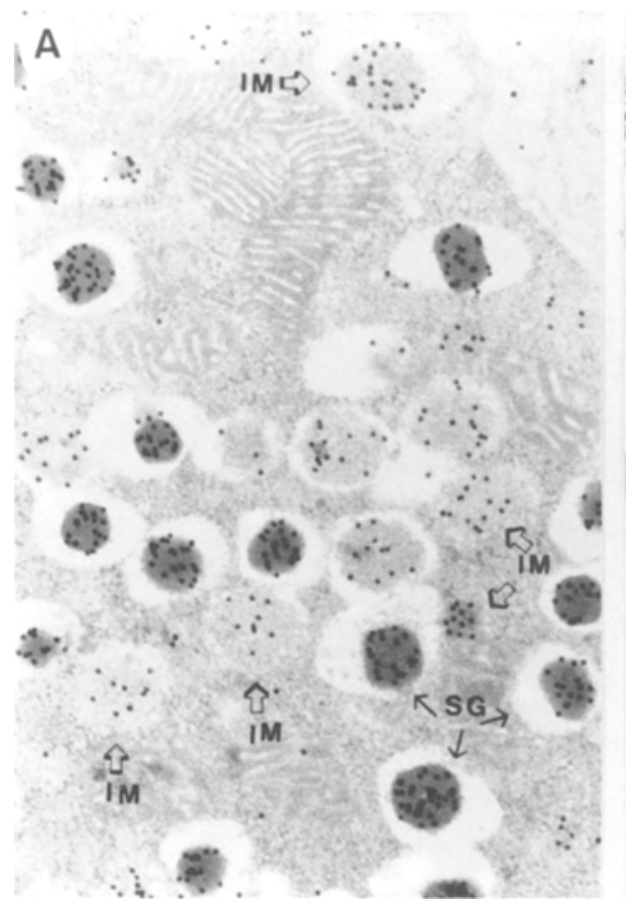

Fig. 3A-C. Electron micrographs of islet Beta cells of control SJL mouse immunostained with (A) anti-insulin antibody, (B) antiHSP60 antibody and (C) anti-proinsulin antibody, detected by the immunogold technique. A Immature (IM) and mature (SG) secretory granules of Beta cells are equally well labelled by anti-insulin
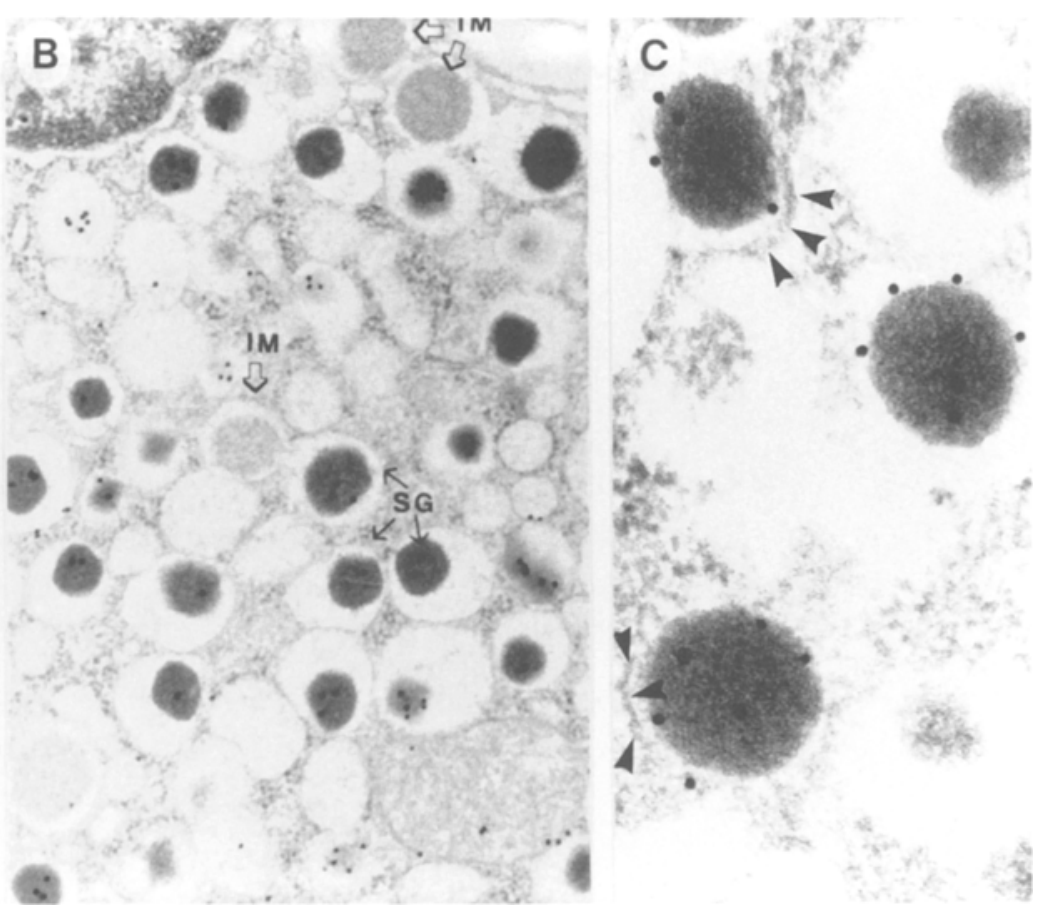

antibodies. B In contrast, anti-HSP60 antibody poorly cross-reacts with immature secretory granules. C The immature granules are characterized by a high proinsulin-reactivity and the presence of clathrin coat (arrowheads) the HSP60 antibody to secretory granules of Beta cells and mitochondria (Table 1). The distribution of gold labelling over six cellular structures (SGs of Beta cells, immature SGs, mitochondria, Golgi apparatus, cytoplasm and SGs of other cell types inside the islet) showed significant differences in mean gold densities (One-way ANOVA, $\mathrm{F}(5 / 119)=27.95, p<0.001)$. The accumulation of gold particles in SGs and mitochondria was significantly higher than the background labelling (T-test, $\mathrm{T}(47)=4.84, p<0.001$ and $\mathrm{T}(34)=4.169, p<0.001$, respectively). On the other hand, immuno-gold labelling of Golgi apparatus and secretory granules from other types of islet cells did not differ significantly from the background (T-test, $\mathrm{T}(20-28)=0.95$ to $0.19, p=\mathrm{NS}$ ). The immature SGs of Beta cells were the least stained cellular structure.

Further analysis of the HSP60 distribution in the Beta cells revealed the existence of small carrier vesicles containing HSP60 immunoreactivity. In many cases these, vesicles appeared to budd off or fuse to SGs (Fig. 4). These vesicles might provide a way of transport of the HSP60 since the low cytoplasm staining with the HSP60 antibody indicates that the HSP60 protein does not exist freely in the cytosol.

By immunoprecipitation and immunoblotting, we have analysed the molecular size of islet cell antigen recognized by HSP 60 antibody. A single $62 \mathrm{kDa}$ protein band was consistently found in islets of control and pre-diabetic NOD mice (Fig.5A,B). The recognition of $62 \mathrm{kDa}$ antigen was specific since control mouse serum as well as HSP60 antibody, pre-cleared with islet lysates prior to immunoblotting, fail to detect the $62 \mathrm{kDa}$ protein band (Fig. 5C). The HSP60 antibody-reactive protein was also present in lysates of rat and human islets cells (Fig. 5 C).

\section{Altered cellular distribution of HSP6O in islet cells of pre-diabetic NOD mice}

The cellular distribution of HSP60-like protein in pancreatic tissue of pre-diabetic NOD mice with advanced insulitis was markedly different from that seen in control mice (Fig.6). Whereas in normal mice, HSP60 was predominantly localized within the dense insulin core of SGs (Fig. 1A, 2, 3B), in the pre-diabetic NOD mice, much of it was found to be localized in the periphery of granules, in the cytoplasm, and, as well, on the cell membranes (Fig. 6A). The accumulation of immunogold on the Betacell membrane was ten times higher in pre-diabetic NOD

Table 1. Density of immunogold labelling with the anti-HSP60 antibody/IgG-gold complex over the different cellular compartments of pancreatic Beta cells of control mice

\begin{tabular}{lc}
\hline Cellular compartment & $\begin{array}{c}\text { Density } \\
\text { (gold particles } / \mu m^{2} \text { ) }\end{array}$ \\
\hline Mature SGs of Beta cells & $69.65 \pm 7.25^{\mathrm{a}}$ \\
Immature SGs of Beta cells & $0.66 \pm 0.46^{\mathrm{a}}$ \\
Mitochondria & $30.32 \pm 4.17^{\mathrm{a}}$ \\
Golgi apparatus & $6.74 \pm 2.97^{\mathrm{b}}$ \\
SGs of other islet cell types & $3.83 \pm 2.60^{\mathrm{b}}$ \\
Background (cytoplasm, nuclei) & $3.71 \pm 1.18^{\mathrm{b}}$ \\
\hline
\end{tabular}

Mean values $\pm \mathrm{SEM}$; ${ }^{a} p<0.001$ vs background, ${ }^{\mathrm{b}} p=\mathrm{NS} ; \mathrm{SG}$, secretory granule 

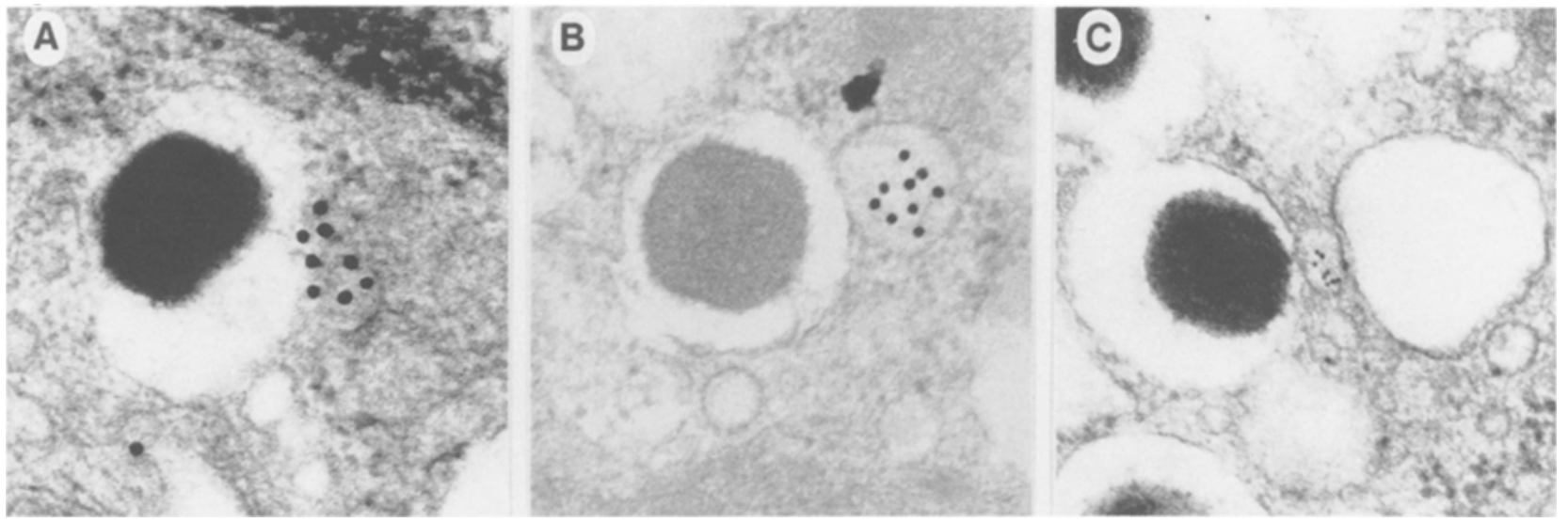

Fig. 4. Identification of carrier vesicles filled with the HSP60 immunoreactivity in Beta cells of healthy, control mice. Sections of the Beta cells immunostained with the HSP60 antibody visualize binding and fusion of the carrier vesicles to secretory granules

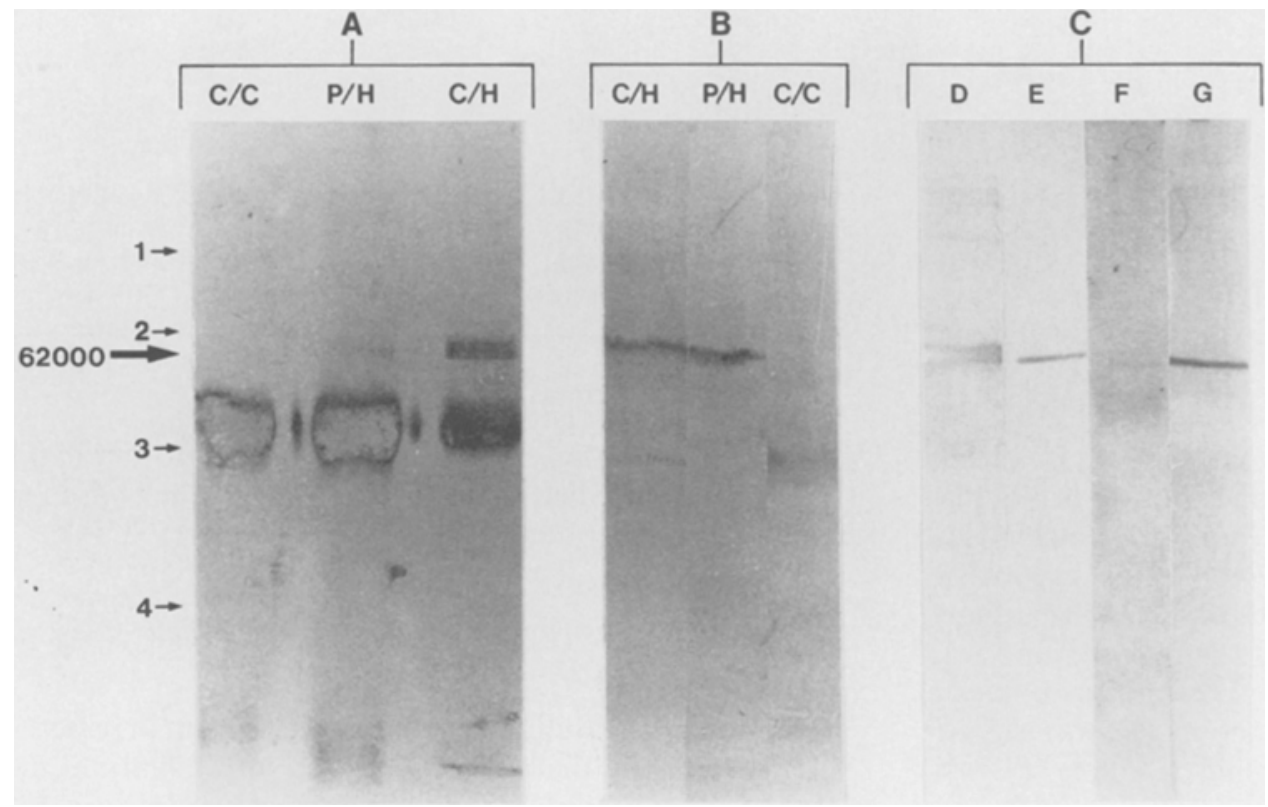

Fig. 5 A-C. Identification of a $62 \mathrm{kDa}$ HSP60 protein in islet cells of human, rat and murine origin. A Immunoprecipitation of islet cell lysates prepared from control mouse $(\mathrm{C}$, lane $\mathrm{C} / \mathrm{C}$ and $\mathrm{C} / \mathrm{H})$ and prediabetic NOD mouse $(\mathrm{P}$, lane $\mathrm{P} / \mathrm{H})$ by normal, control mouse serum $(\mathrm{C}$, lane $\mathrm{C} / \mathrm{C})$ and $\mathrm{HSP} 60$ antibody $(\mathrm{H}$, lane $\mathrm{P} / \mathrm{H}$ and $\mathrm{C} / \mathrm{H})$. B Western blot of islet cell lysates from control $(\mathrm{C}$, lane $\mathrm{C} / \mathrm{C}$ and $\mathrm{C} / \mathrm{H})$ and pre-diabetic mice $(\mathrm{P}$, lane $\mathrm{P} / \mathrm{H})$ probed with normal, control mouse serum $(\mathrm{C}$, lane $\mathrm{C} / \mathrm{C})$ and $\mathrm{HSP} 60$ antibodies $(\mathrm{H}$, lane $\mathrm{P} / \mathrm{H}$ and $\mathrm{C} / \mathrm{H})$. C Immunoblotting analysis of proteins in human (D) and rat islet

mice than in healthy, control mice $(1.7 \pm 0.22$ and $0.17 \pm 0.07$ gold grains per $\mu \mathrm{m}$, respectively, $\mathrm{T}(12)=4.259$, $p<0.01$ ). Also, the number of gold particles located outside the dense insulin core was significantly higher in prediabetic than in control mice (T $(38)=4.1876, p<0.001)$ with the evident decrease in the number of gold particles located inside the insulin core in pre-diabetic mice $(\mathrm{T}(38)=3.2856, p<0.002$ ) (Fig. 7).

The reduction of the HSP60 antibody binding to SGs was associated with the insulin core relaxation. The aver- cell lysates (E) recognized by HSP60 antibody. Purified HSP60 antigen from Chinese hamster ovary cells was used as a positive control and molecular weight standard $(G)$. The specificity of HSP60 antigen recognition in rat islet cells is indicated by lack of respective band staining by HSP60 antibody pre-cleared with islet cell lysate before immunoblotting (F). Numbers 1 to 4 indicate positions of the molecular weight standards: 97400 (phosphorylase B), 66200 (bovine serum albumin), 42700 (ovalbumin), 21500 (soybean trypsin inhibitor)

age insulin core diameter increased from $175.9 \pm 37.9 \mathrm{~nm}$ (SD) in control animals to $210 \pm 45.18 \mathrm{~nm}$ (SD) in the mature SGs of pre-diabetic mice respectively, and this difference was highly significant $(\mathrm{T}(158)=5.15, p<0.001)$.

Examination of numerous electron micrographs of pancreata from pre-diabetic NOD mice also revealed certain morphological changes in the islet cells. The most visible one was an increased number of immature SGs (Fig.6B). The fusion between mature and immature SGs was also found to be a more common phenomenon in in- 


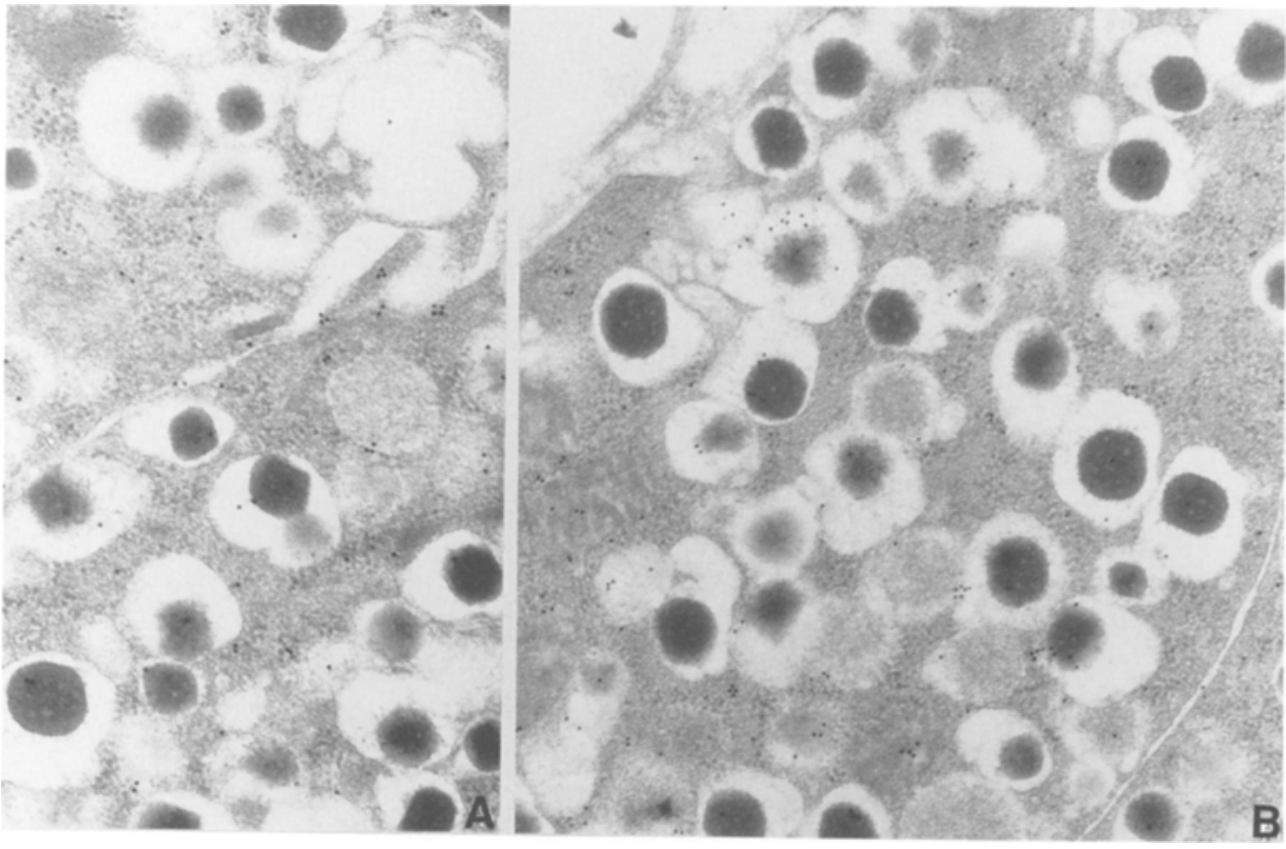

Fig.6A, B. Thin sections of islet Beta cells illustrating the alterations in distribution of the HSP60-related protein in a 13week-old pre-diabetic female NOD mouse. These abnormalities include: a reduced binding to secretory granules and increased binding to the cytoplasm ( $\mathbf{A}$ and $\mathbf{B}$ ), and increased binding to the Beta-cell surface membrane (A)

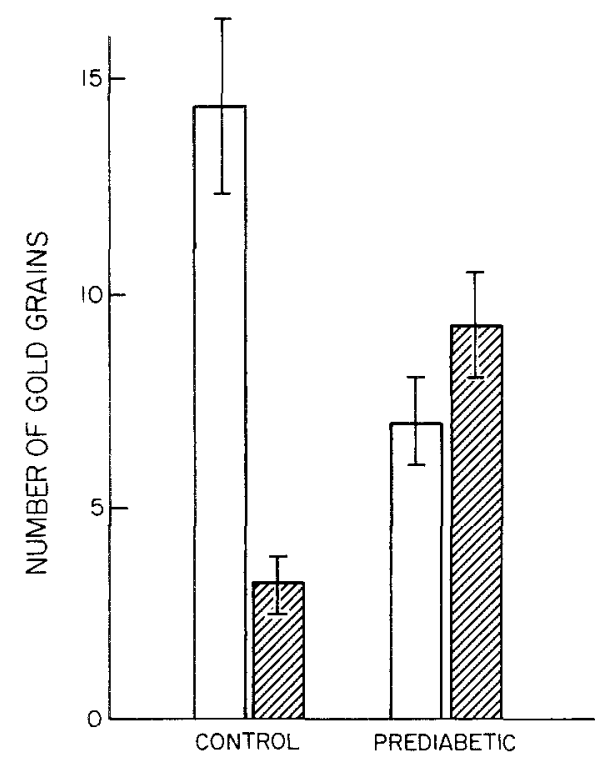

Fig. 7. Histogram showing the distribution of the HSP60 inside ( $\square$ ) and outside $(\mathbb{Z})$ the dense insulin core of secretory granules in islets from control and pre-diabetic NOD mice detected by immunogold technique. The columns represent the mean values ( \pm SEM) of number of gold particles found inside the insulin core and in the space surrounding the core

filtrated islets as compared to normal cells (Fig.6B). To assess whether the number or relative maturity of SGs differ in healthy and pre-diabetic mice, micrographs of three separate Beta cells for three pre-diabetic and three control mice were quantitatively analysed using a Bioquant System. The mean number of mature SGs in pre-diabetic and control mouse Betacells was $2.65 \pm 0.95$ and $2.77 \pm 0.37$ (SD) per square $\mu \mathrm{m}$, respectively. The mean number of immature granules was $0.52 \pm 0.16$ and $0.17 \pm 0.06$ (SD) per square $\mu \mathrm{m}$ of Beta cells of prediabetic and control mice, respectively. Therefore, in
Beta cells of pre-diabetic NOD mouse every fifth secretory granule is immature compared to a one-to- 15 ratio in healthy mice while the number of the mature granules is almost equal. This result indicates that the maturation process of SGs is less complete in pre-diabetic NOD mice, compared to control mice.

To determine whether there is a relationship between the observed alteration in HSP60 distribution to the progression of insulitis, pancreatic sections taken from individual NOD mice were examined histologically for the presence of insulitis and by electron microscopy for the distribution of HSP60 antibody binding sites. Spontaneous incidence of insulitis in our NOD mice colony, expressed as a percentage of affected islets in a given age group, was approximately 47,85 and $100 \%$ at age 5,7 and 10 weeks, respectively, in female NOD mice. Representative electron micrographs from islets at each stage of insulitis (Fig. $8 \mathrm{~A}-\mathrm{C}$ ) illustrate sequence of progressive reduction of the HSP60-antibody binding to insulin secreting granules (Fig. 8D-F) and increased HSP60 antibody binding to cytoplasm in islets with severe insulitis (stage F). The alteration in localization of the HSP60 antibody binding sites occurs, at the beginning, in non-lysed, non-necrotic Beta cells (Fig. 8E), and is evident in necrotic cells (Fig. 6A,B). (The cell viability at the electron microscopic level has been judged from electrondensity of cytoplasm, preservation of intact structures by cellular organelles, and continuity of cell membrane).

\section{Discussion}

We have documented here by immunoblotting and immunogold ultracytochemistry that antibodies to the mammalian HSP60 chaperonin protein specifically cross-react with the $62 \mathrm{kDa}$ protein located to SGs and mitochondria of pancreatic islet cells. The specificity of binding to SGs 

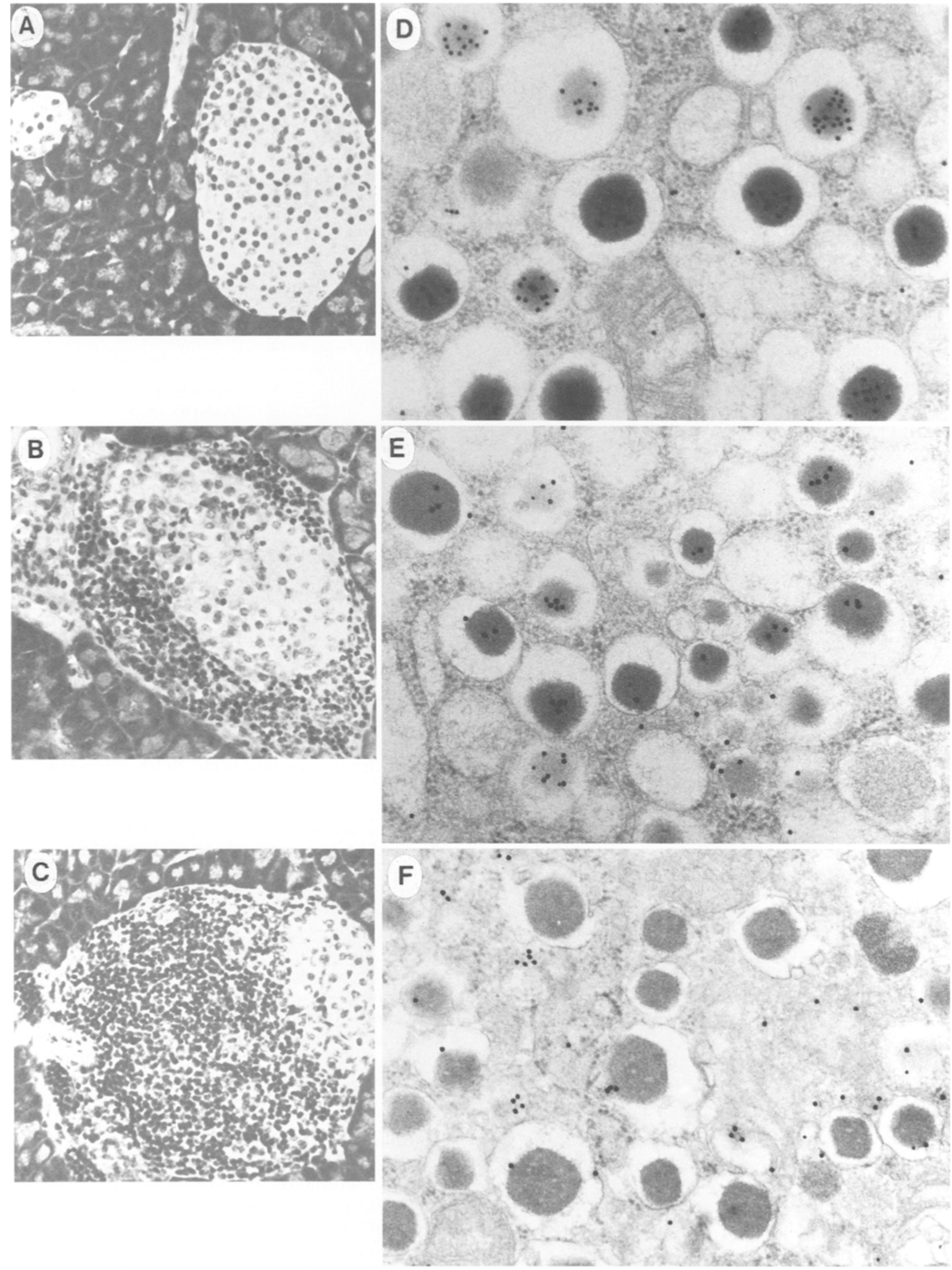
was supported by the fact that normal rabbit sera or unrelated sera (normal mouse or human serum) did not result in any granular or mitochondrial staining following immunocytochemistry, and that HSP60 antibody pre-adsorbed to islet cell lysates prior to immunoblotting failed to detect the $62 \mathrm{kDa}$ islet cell antigen on Western blots. The quantitative analysis of the distribution of HSP60 antibody binding sites in different cellular compartments confirmed the preferential concentration of these sites in SGs of Beta cells and mitochondria.

While binding of the HSP60 antibody to mitochondria was expected [4-7], the observed binding to SGs is a novel finding. Thus far, members of the HSP60 family, which play an important role in protein folding and assembly processes [4-7], have only been identified in eucaryotic organelles such as mitochondria and chloroplasts. In this context, our localization of HSP60 cross-reactive protein in SGs, might suggest that HSP60-related proteins are also present outside of mitochondria. Whether or not they are carrying similar, molecular chaperone functions is not yet known.

Our data indicate that HSP60-related protein is constitutively expressed in secretory granules under physiological conditions, and its abundance shows marked variation with a degree of maturity of SGs. The highest number of HSP60 immunoreactive sites were observed in the mature granules of insulin-secreting Beta cells, whereas little reactivity was seen in immature proinsulin-rich vesicles. In maturing and mature granules, HSP60 antigen was located predominantly over the dense insulin core. One possible explanation for the observed specific localization of the HSP60-related protein to the central core of mature secretory granules is that this protein might be involved in the granular maturation associated with the assembly of the insulin core.

The biosynthetic pathway by which the HSP60-related protein is targetted to SGs has yet to be elucidated. The fact, that the Golgi apparatus and the immature secretory granules of Beta cells were poorly stained with the HSP60 antibody suggests that the HSP60-related protein may not be transported to secretory granules along the same pathway as insulin. An alternative model for transport of molecules from one cellular compartment to another via carrier vesicles has been recently proposed [23]. We have made an intriguing observation on the existence of such vesicles containing HSP60 cross-reactive material. However, whether or not these vesicles play any role in the transport/delivery of HSP60-related protein to SGs remains to be investigated.

Another novel observation reported here is that in prediabetic NOD mice with advanced insulitis, cellular distribution of HSP60-related protein was markedly differ-

Fig. 8 A-F. Changes in HSP60 protein distribution within insulinsecreting Beta cells of female NOD mice in relation to progression of insulitis. The comparison of alterations in distribution of HSP60antibody binding sites ( $\mathbf{D}, \mathbf{E}$ and $\mathbf{F}$ ) in islets at each stage of insulitis $(\mathbf{A}, \mathbf{B}$ and $\mathbf{C})$ in 5-, 8-and 13-week-old NOD mice, respectively. Mice used in this study were pre-diabetic with plasma glucose and insulin in normal range ent from that seen in control animals. The HSP60 in this case was not localized within the insulin core of SGs, but was distributed at various other sites within cells including the periphery of the SGs, cytoplasm, and the cell membrane. The alteration in distribution of the HSP60-related protein seemed to occur as a result of insulitis since the loss of the binding of HSP60 antibody to insulin granules was gradual and correlated well with progression of islet cell inflammation. The most visible consequence associated with the HSP60 redistribution was an increase in the insulin core diameter and accumulation of immature granules.

The observed insulitis-related changes in distribution of the HSP60-related protein and the associated changes in SG maturity may suggest a role for the HSP60 in normal Beta-cell physiology. Also, in view of the strongly antigenic nature of homologous mycobacterial proteins $[1-3,8]$, the abnormal distribution of HSP60-related protein in pre-diabetic NOD mice may lead to the appearance of new antigenic sites and contribute to the development of autoimmunity. The identification of $T$ cells and antibodies cross-reactive with the $65 \mathrm{kDa}$ mycobacterial heat-shock protein in the blood of newly-diagnosed diabetic NOD mice $[13,14]$ seemed to support this supposition. Furthermore, the stimulation of mouse diabetogenic T-cell clones by recombinant human HSP60 or specific synthetic peptide derived from it, provides additional evidence that the autoantigen is related to the HSP60 [14, 24]. Although the exact nature and function of the HSP60-related protein of Beta-cell SGs is not yet known, its possible relationship with autoimmune insulindependent diabetes warrants further investigation.

Acknowledgements. We thank Dr. D. Hill for helpful comments on the manuscript. This work was supported by the Bickell Foundation (Toronto, Ontario Canada).

\section{References}

1. Young D, Lathigra R, Hendrix D, Sweetser D, Young RA (1988) Stress proteins are immune targets in leprosy and tuberculosis. Proc Natl Acad Sci USA 85: 4267-4270

2. Young RA (1990) Stress proteins and immunology. Annu Rev Immunol 8: 401-420

3. Young DB, Mehlert A, Smith DF (1990) Stress proteins and infectious diseases. In: Morimoto RI, Tissieres A, Georgopoulos C (eds) Stress proteins in biology and medicine. Laboratory Press Cold Spring Harbor New York, pp 131-165

4. Ellis JR, Hemmingsen MS (1989) Molecular chaperones: proteins essential for the biogenesis of some macromolecular structures. TIBS 14: 339-342

5. Rothman JE (1989) Polypeptide chain binding proteins: catalysts of protein folding and related processes in cells. Cell 59: 591-601

6. Hemmingsen SM, Woolford C, van der Vies SM et al. (1988) Homologous plant and bacterial proteins chaperone oligomeric protein assembly. Nature 333 : 330-334

7. Hallberg RL (1990) A mitochondrial chaperonin: genetic, biochemical and molecular characteristics. Seminar in Cell Biol 1: $37-45$

8. Kaufmann SHE, Schoel B, Wand-Wurttenberger A, Steinhoff U, Munk ME, Koga T (1990) T-cells, stress proteins and pathogenesis of Mycobacterial infections. Curr Top Microb Immunol 155: 125-141 
9. Holoshitz J, Matitau A, Cohen IR (1984) Arthritis induced in rats by cloned $T$ lymphocytes responsive to mycobacteria but not to collagen II. J Clin Invest 73: 211-215

10. Van Eden W, Holoshitz J, Nevo Z, Frenkel A, Klajman A, Cohen IR (1985) Arthritis induced by a T lymphocyte clone that responds to Mycobacterium tuberculosis and to cartilage proteoglycans. Proc Natl Acad Sci USA 82: 5117-5128

11. Van Eden W, Hogervorst EJM, van der Zee R, van Embden JDA, Hensen EJ, Cohen IR (1989) The mycobacterial $65 \mathrm{kD}$ heat shock protein and autoimmune arthritis. Rheumatol Int 9: 187-191

12. McLean L, Winrow V, Blake D (1990) Current status review: Role of immunity to mycobacterial stress proteins in rheumatoid arthritis. J Exp Pathol 71: 295-303

13. Elias D, Markovits D, Reshef T, van der Zee R, Cohen IR (1990) Induction and therapy of autoimmune diabetes in the non-obese diabetic (NOD/Lt) mouse by a $65-k D$ a heat shock protein. Proc Natl Acad Sci USA 87:1576-1580

14. Elias D, Reshef T, Birk OS, van der Zee R, Walker MD, Cohen IR (1991) Vaccination against autoimmune mouse diabetes with a $\mathrm{T}$ cell epitope of the human $65 \mathrm{kDa}$ heat shock protein. Proc Natl Acad Sci USA 88: 3088-3091.

15. Tochino Y, Kanaya T, Makino S (1982) Genetics of NOD mice. In: Minura G, Baba S, Goto Y, Kobberling Y (eds) International symposium on clinico-genetic genesis of diabetes mellitus. (Kobe, Japan) International Congress Series, No 597, pp 285291

16. Miller BJ, Appel MC, O'Neil JJ, Wicker LS (1988) Both Lyt $2^{+}$ and $\mathrm{L} 3 \mathrm{~T} 44^{+} \mathrm{T}$ cell subset are required for the transfer of diabetes in non-obese diabetic mice. J Immunol 140: 52-58

17. Gupta RS, Dudani AK (1987) Mitochondrial binding of a protein affected in mutants resistant to the microtubule inhibitor podophyllotoxin. Eur J Cell Biol 44: 278-285
18. Jindal S, Dudani AK, Singh B, Harley CB, Gupta RS (1989) Primary structure of a human mitochondrial protein homologous to the bacterial and plant chaperonins and to the 65 kilodalton mycobacterial antigen. Mol Cell Biol 9: 2279-2283

19. Bendayan M, Zollinger M (1983) Ultrastructural localization of antigenic sites on osmium-fixed tissues applying the protein $\mathrm{A}$ gold technoque. J Histochem Cytochem 31: 101-109

20. Orcil, Ravazzola M, Amherdt M, Madsen O, Vassali J-D, Perrelet A (1985) Direct identification of prohormone conversion site in insulin-secreting cells. Cell 42: 671-681

21. Lacy PE, Kostianovsky M (1967) Methods for isolation of intact islets of Langerhans from the rat pancreas. Diabetes 16: 35-59

22. Morimoto RI, Tissieres A, Georgopoulos C (1990) The stress response, function of the proteins and perspectives. In: Morimoto RI, Tissieres A, Georgopoulos C (eds) Stress proteins in biology and medicine. Laboratory Press, Cold Spring Harbor New York, pp 1-36

23. Griffiths G, Gruenberg J (1991) The arguments for pre-existing early and late endosomes. Trends in Cell Biol 1:5-9

24. Cohen IR (1991) Autoimmunity to chaperonins in the pathogenesis of arthritis and diabetes. Annu Rev Immunol 9:567-589

Received: 17 September 1991

and in revised form: 26 November 1991

Dr. K.Brudzynski

The John P. Roberts Research Institute

University of Western Ontario

100 Perth Drive

London, Ontario N6A $5 \mathrm{~K} 8$

Canada 